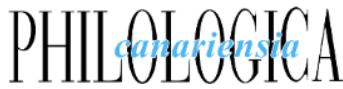

Philologica Canariensia 21 (2015), 81-107 eISSN: 2386-8635

DOI: 10.20420/PhilCan.2015.0035

\section{ESOS NEGROS PARAOS: HUMOR, GUFEO Y SUBVERSIÓN EN LA POESÍA NIUYORRIQUEÑA}

\author{
ALEJO LÓPEZ \\ Instituto de Investigación en Humanidades y Ciencias de la Educación \\ Universidad Nacional de La Plata - CONICET, Argentina
}

\section{RESUMEN}

El humor ocupa un lugar central en la poética desplegada por los poetas de la diáspora puertorriqueña en los Estados Unidos. El humor irreverente e impertinente (bautizado con el neologismo spanglish el gufeo $^{1}$ ) de poetas como Víctor Hernández Cruz, Pedro Pietri o Tato Laviera exhibe la potencia desbordante de este humorismo de raíz afro-antillana que atraviesa la tradición poética niuyorriqueña, al tiempo que se revela como uno de los instrumentos más eficaces en la política cultural contra-discursiva desarrollada por esta tradición contestataria.

PALABRAS ClAVE: poesía niuyorriqueña, humor, Víctor Hernández Cruz, Pedro Pietri, Tato Laviera

Those Black Paraos: Humor, Gufeo and Subversion in Nuyorican Poetry

\section{ABSTRACT}

Humor plays a central role in the poetics displayed by the poets of the Puerto Rican diaspora in the United States. The irreverent and impertinent humor (called by the Spanglish neologism gufeo) of poets like Victor Hernandez Cruz, Pedro Pietri or Tato Laviera exhibits the overwhelming power of this Afro-Antillean humor that goes through the Nuyorican poetic tradition, while it becomes one of the most effective tools in the counter-discursive cultural policy developed by this agonistic tradition.

KEYWORDS: Nuyorican poetry, humor, Víctor Hernández Cruz, Pedro Pietri, Tato Laviera 


\section{INTERFERENCIA Y TRANS-CREACIÓN EN LA LITERATURA NIUYORRIQUEÑA}

Miguel Algarín, uno de los fundadores del movimiento niuyorriqueño, señala que el emigrado puertorriqueño en Nueva York tenía ante sí tres opciones: trabajar como un esclavo asalariado, procurarse la vida fuera del marco de la ley, o crear un comportamiento alternativo $(1975,9)$. Este comportamiento alternativo es el que dio origen a la literatura nuyorican o niuyorriqueña, ${ }^{2}$ tradición iniciada por un grupo de poetas que llenaron por medio de la palabra poética ese "hiato existencial" (López, 2012) que configuraba la naturaleza diaspórica y extraterritorial de su identidad cultural. De ahí que estos poetas fundaran una poesía polifónica que, como he señalado en otro lugar, los enredaba en la zona liminar de un perpetuo entremedio, una vida tensada entre lo insular puertorriqueño y lo continental norteamericano, "entre el español y el inglés, entre el ámbito privado de la familia y el espacio público dominado por la cultura WASP, 3 entre la lengua escrita del canon y el coro plurilingüe de la calle, entre la defensa de una autonomía frente a la nación hegemónica y la pertenencia a ese mismo espacio hegemónico" (López, 2012), un entremedio que representa, como señala Jean Franco (en Flores, 1993, 9), algo que no puede ser asimilado.

Como expresión de esta nueva consciencia identitaria surge así una estética fundada en el descentramiento: extraterritorialidad, 4 cruces y fugas respecto a las tradiciones nacionales y a los marcos genéricos, discursos heterogéneos que se construyen sobre la variación de la oralidad, sobre la lengua como práctica, como habla. Todos estos rasgos confluyeron en una tradición que irrumpió como una poética del entremedio y una interferencia. La literatura niuyorriqueña surge como una verdadera interferencia dentro de los marcos de producción en los que se inscribe. La interferencia es ese fenómeno por el cual se altera, modifica o destruye una señal durante su trayecto en el canal existente entre el emisor y el receptor. En la interferencia electroacústica en medio del tránsito de una señal de onda se produce una distorsión que hace que entre la señal de entrada y la señal de salida haya una diferencia. La poesía niuyorriqueña es ese entremedio que genera la interferencia entre los materiales y tradiciones que entran en su sistema poético y la distorsión poética que resulta de estos bordeamientos. Es una interferencia que desestabiliza cualquier binarismo y amenaza las identidades en las cuales se fundan los polos de lo insular y lo continental puertorriqueño, lo hispánico y lo anglo-norteamericano, e incluso lo propiamente latinoamericano. 5 
Esta poética disruptiva intervino dentro del entramado cultural norteamericano a través de lo que Juan Flores y George Yúdice (1993) denominaron la "trans-creatividad" de las culturas latinas en los Estados Unidos, esto es, su capacidad de usufructuar las lindes como espacios de creación, forjando así nuevos sentidos identitarios por fuera de las tradicionales categorías duras del territorio, la nación o las lenguas nacionales. Uno de estos mecanismos trans-creativos lo constituye aquello que la crítica puertorriqueña Frances Aparicio denominó la "tropicalización” de la literatura latina en los Estados Unidos. A partir de su lectura de los versos del poeta niuyorriqueño Víctor Hernández Cruz, Aparicio ubica la tropicalización como el rasgo distintivo de las poéticas latinas en los Estados Unidos. Esta tropicalización constituiría una resistencia a los procesos de asimilación al intervenir tanto sobre las construcciones hegemónicas de la identidad y la cultura norteamericanas, como sobre las construcciones hegemónicas de la identidad latina en tanto "otro" de esa sociedad y cultura hegemónicas. Para Aparicio tanto la "trans-creación" como la "tropicalización" configuran verdaderas políticas de representación:

Both transcreation and tropicalization propose multidirectional modes of engaging in the politics of representation by examining the shifting semantics of cultural signifiers, the flux of appropriations and re-appropriations that characterizes cultural identity and cross-cultural dynamics, and by allowing the voices and signifiers of Latinos and Latinas to reclaim our always already tropicalized "tropics" as a cultural site of our own. (1994, 795-96)

Esta intervención y auto-afirmación de la cultura e identidad latinas en los Estados Unidos por medio de su tropicalización de los significantes culturales norteamericanos se desprendería, principalmente, del modo en que la literatura latina se reapropia de la(s) lengua(s) procediendo a introducir en ella(s) otros registros, acentos y ritmos que le son propios. Así, por ejemplo, la subversión operada por la lengua poética de Víctor Hernández Cruz en su poema "Song 2", surge, precisamente, del trabajo con la hibridación lingüística y el cambio de código entre inglés y español, y del efecto humorístico que estas operaciones lingüísticas producen en el texto:

All the old Chevies that the gringoes from up state New York 
wore out

Were sailing around the neighborhood

with dices and San Martín de Porres

el negrito who turned catholic

Hanging in the front windows $(1989,82)$

El humor que produce el poema de Hernández Cruz no sólo surge del trabajo lingüístico con el spanglish sino también, como señala Aparicio, de las subversiones culturales e identitarias que subyacen bajo cada verso ("sub-verso"), esto es, del trabajo con los procesos transculturadores que configuran la identidad cultural niuyorriqueña, y de la representación humorística de la situación marginal de esta cultura frente al patrón dominante de la sociedad norteamericana. El calco sintáctico por medio del cual Hernández Cruz introduce la sufijación plural del inglés dentro del término español "gringo" (gringoes) no sólo apela a la comicidad por medio de la representación del habla interlingüe de la comunidad latina en los Estados Unidos, sino que también establece una identificación y complicidad (luego problematizadas) con el lector al ubicar al sujeto de la enunciación dentro del colectivo de lo "latino" frente a la comunidad "gringa", a la cual pertenecen los autos maltrechos que se venden en el barrio. Esta identificación es luego problematizada cuando el sujeto poético describe a San Martín de Porres, el santo que estos mismos latinos colocan en sus autos como significante cultural representativo de su identidad de raíz hispanoamericana. El santo aparece descrito como "el negrito que se volvió católico", enunciación que establece una distancia reforzada por la humorada de la descripción, y que vuelve problemática la identificación anteriormente establecida entre el sujeto poético y la comunidad latina. El humor y la hibridez de este sujeto de enunciación se intensifican si pensamos que la descripción de San Martín de Porres, el primer santo mulato de América, ${ }^{6}$ apela a su "asimilación" frente a la cultura europea durante la colonización del continente.

\section{CHOTEO, GUACHAFITA Y GUFEO: HUMOR Y CARNAVALIZACIÓN ANTILLANA}

El tipo de humoricidad desarrollada por el poema de Hernández Cruz luce todavía atenuada en comparación con la potencia desfachatada de ese otro tipo de humor al que apelará la poesía niuyorriqueña: la irreverencia antillana. La carcajada antillana surge del poder corrosivo del choteo, la guachafita y el relajo y no de un humor todavía apegado a la doble significación que exige una lectura intertextual, 
y en cierta medida intelectual, de ciertas relaciones y paradojas de la cultura latinoamericana.

Se trataría, en principio, de la diferencia entre el humorismo y la comicidad, tal como la concibe Umberto Eco en su ensayo "Lo cómico y la regla”, donde el semiólogo italiano analiza lo cómico como una violación de las reglas socio-culturales presupuestas y por ende reafirmadas en su aserción tácita. Para Eco "el humorismo no sería, como lo cómico, víctima de la regla que presupone, sino que representaría su crítica consciente y explícita. El humorismo sería siempre metasemiótico y metatextual" (1999, 285). Eco desestima la comicidad desenmascarando la falacia que subyace bajo la idea de que la risa cómica subvierte el orden que aparentemente negaría por medio de su inversión, parodización, degradación, etc. Para Eco lo cómico, y la carnavalización asociada a ello como instancia de comicidad libertada socialmente, es sólo un mecanismo de control social oculto bajo el velo de una libertad aparente: se posibilita el espectáculo del libertinaje y el placer de la risa junto con la violencia inmanente a toda comicidad burlesca pero dentro de los límites espacio-temporales y culturales impuestos por el orden vigente. A diferencia de este control impuesto bajo la máscara del libertinaje, Eco rescata el humorismo a través de su capacidad reflexiva por medio de la crítica social, promoviendo una revelación intelectual por la cual "la carcajada se transforma en sonrisa” (1999, 284). Para Eco este humor reflexivo e intelectual es "un carnaval frío" $(1989,20)$ que apaga la risotada inconducente y la ahoga en la serenidad amarga del conocimiento y la revelación.

Lo que no logra vislumbrar Umberto Eco desde su perspectiva eurocéntrica es que, además de la occidental cultura medieval del carnaval, que él toma como modelo del análisis de Mijail Bajtín (1989), existen otras prácticas culturales que entrañan procesos de carnavalización significativamente diferentes a estos modelos europeos como son los de la cultura antillana del choteo y la guachafita, expresiones de una cultura lúdica y jocosa en las cuales la carnavalización no encuentra limitaciones espacio-temporales y opera por tanto desreguladamente y con un grado de subversión superlativo. A su vez, hay que señalar que los procesos de carnavalización que ponen en juego poéticas como las del niuyorriqueño Tato Laviera o el puertorriqueño Luis Rafael Sánchez muestran cómo a diferencia de la lectura que hacía Mijail Bajtín del carnaval y sus usos en la literatura europea, en la cultura latinoamericana, y especialmente en la cultura antillana, el carnaval y la carnavalización no son ya meros espectáculos especularizados del carnaval medieval. Si bien en la Europa moderna, tal como 
afirmaba Bajtín, el carnaval en tanto acontecimiento popular ya ha dejado de existir desde Rabelais en adelante, deviniendo, por consiguiente, sus reapropiaciones modernas en un espectáculo en el cual "los contactos se intelectualizan y se formulan en un discurso vacío que preserva los signos (pero sólo los signos) de una situación carnavalesca que ya no existe” (Jenny, 1974, 21, mi traducción), en la cultura latinoamericana, en cambio, la experiencia lúdica y fruitiva del carnaval en tanto acontecimiento popular no sólo sigue vigente sino que es la fuente de numerosas expresiones culturales que se valen de esta potencia popular para sostener sus producciones estéticas. Como señala Emir Rodríguez Monegal a propósito del carnaval en la teoría bajtiniana y sus usos en la crítica literaria latinoamericana, las operaciones de carnavalización cultural se encuentran en la base de nuestras raíces culturales y constituyen una experiencia vital y popular todavía vigente:

Desde los orígenes de nuestra cultura, el proceso brutal de asimilación de culturas ajenas, el choque producido por la violenta imposición de un punto de vista cristiano y feudal del mundo y más tarde la masiva importación de otra cultura ajena (la africana, aportada por esclavos), todo esto llevó a formas extremas de carnavalización....

Bakhtin [sic] tiene probablemente razón al alegar que el Carnaval (tal como era representado en la Edad Media y en el Renacimiento) ya no existe en Europa a partir de la Edad Moderna. Después de Rabelais, ha perdido para siempre sus rasgos principales de ser a la vez un acontecimiento folklórico y popular. Pero en América Latina, el Carnaval está aún vivo: especialmente en el área del Caribe y en el Brasil. El conflicto y la mezcla de culturas (indígenas, europeas, negras) en estas áreas privilegiadas han impedido que el Carnaval se convirtiese sólo en una institución oficial exclusivamente fiscalizada por el Gobierno. (1979, 407-408)

De aquí se desprende el hecho de que el humor carnavalesco que atraviesa, ciertamente, gran parte de la cultura popular latinoamericana, y muy especialmente la cultura popular afro-antillana, comporte una clara condición política contra-discursiva. Esta humoricidad popular de raíces africanas se inserta, a su vez, en una tradición afro-descendiente mayor atravesada por aquello que Henry Louis Gates (1988) definió para la cultura afro-americana como el "tropo de los esclavos": el ritual del $\operatorname{signifyn}(g)$. 
Este tropo de las culturas negras engloba, y subvierte a la vez, varios otros tropos, por medio de la repetición y la inversión, y se vale, fundamentalmente, de procedimientos como la ironía, la parodia y el quiasmo con el fin de subvertir un discurso "otro" e inscribir, veladamente, el propio. Se trata de una práctica cultural heredada de la mitología yoruba (y, por tanto, acervo común con la tradición cultural afro-antillana), ${ }^{7}$ que se expresa a través de los discursos arteros y sutiles por medio de los cuales los esclavos negros, valiéndose muchas veces del humor, desarrollaron sus tácticas de resistencia y supervivencia cultural.

Como señala John Morreall en su ensayo sobre la filosofía del humor Taking Laughter Seriously (1983), la risa exhibe su mayor potencial emancipatorio en el dominio de la política, por cuanto es aquí donde el sujeto capaz de tomarse para la risa lo incongruente de la condición política logra situarse, en cierto punto, por encima de ella y por fuera del alcance de sus fuerzas represivas en la medida en que, incluso en condiciones de reclusión, "preserva algo de su libertad, si no de movimiento, sí al menos de pensamiento" (1983, 101, mi traducción). La potencia de la risa trasciende, en verdad, su capacidad de instituirse en una estrategia de resistencia política y alcanza la potencia de configurar una verdadera ética contra-hegemónica al subvertir los valores, tradiciones y sistemas morales estatuidos por medio de una fuerza pulsional que busca "violar incluso lo que se supone inviolable: el orden racional de las cosas" (en Morreall, 1983, 103). Esta potencia contra-hegemónica e irracional de la risa emerge plenamente en la naturaleza excesiva e irreverente del humor antillano y en su origen marginal, pero poco tiene que ver con la "calma reflexión filosófica" $(1983,105)$ que, según Morreall, promueve el humor a través de la distancia que establece entre el sujeto que ríe y aquello de lo que ríe. Esto último se acercaría al concepto reflexivo del humorismo que defendía Umberto Eco pero con una función que, contrariamente a la postulada por Eco, en Morreall se orienta al control social por medio de diversos mecanismos de expurgación que permiten el equilibramiento de los excedentes dentro del sistema, una funcionalidad social del humor que es rescatada por teorizaciones del humor en tanto "desahogo o liberación" de ciertas pulsiones humanas (aquello que se conoce como relief/release theory).

El humor de la cultura popular afro-antillana, por el contrario, no se sostiene en la necesidad de alejarse o recluirse de la realidad para poder verla objetivamente a través de una distancia que promueva la crítica reflexiva, sino que, por el contrario, la jocosidad antillana encuentra su fuerza ética en la posibilidad de desarticular el 
opresivo aparato socio-cultural hegemónico a través de la insurrección irrespetuosa de la carcajada y el relajo. Como señalamos anteriormente, la carnavalización del relajo antillano implica la trasgresión de las interdicciones sociales, no a través de ese gran paréntesis controlado que es el carnaval europeo, sino a través del exceso sensual y fruitivo de la cultura lúdica e irreverente del vacilón, de la propensión de "tirar todo a relajo" desconociendo y, por tanto, desautorizando el orden moral y ético que se impone a diario. La jocosidad desenfadada de ciertos poemas de Víctor Hernández Cruz participa de esta expresión cultural antillana del relajo o vacilón que en Cuba se denominó “choteo", en Puerto Rico "guachafita” y que los niuyorriqueños recuperaron por medio del neologismo spanglish el "gufeo".

En su célebre ensayo Indagación del choteo cubano (1928) señalaba Jorge Mañach que esta práctica cultural poseía un carácter "tóxico" a partir de su naturaleza insurrecta, tal como se desprende de la definición que da Mañach del choteo: "un hábito de irrespetuosidad- motivado por un mismo hecho psicológico: una repugnancia a toda autoridad" (1969: 19). Esta actitud anárquica, antes que responder a una consciente acción política de resistencia, surge, para Mañach, de la propia naturaleza cubana y su incapacidad "congénita" de someterse a la autoridad. La práctica del choteo, señalaba a su vez el antropólogo cubano Fernando Ortiz, se hallaba enraizada principalmente en el estrato afro-descendiente de la sociedad cubana, cuyo "inextinguible buen humor" y "espíritu burlesco" le brindaba un mecanismo de defensa y resistencia frente a la inclemencia que su situación de marginalización y sometimiento les procuraba, constituyendo así un instrumento de resistencia caracterizado por una "desbordada fluencia satírica, que a veces llega a sarcástica” (en Valdés García, 2004, 57). A través del carácter irrespetuoso y sarcástico del choteo los negros lograban resistir y trasgredir la subordinación de la que eran objeto bajo el sistema colonial, invirtiendo a través de la burla y la ironía la jerarquía instaurada entre amo y esclavo, al tiempo que por medio de lo que Mañach llamaba la "parejería" del choteo cubano, nivelaban, aunque no fuera más que discursivamente, las relaciones de poder que los sometían, logrando así intervenir el espacio público al no reconocer ya distancias entre las esferas de lo público y lo privado.

Esta forma irreverente y popular del humor antillano, que en Puerto Rico se conoce como la "guachafita", consiste en una actitud lúdica y provocativa frente a las situaciones cotidianas más serias, lo cual genera un humor ácido y satírico, regodeándose en la dislocación del interlocutor frente a la situación planteada y en la 
imposibilidad de determinar con certeza la naturaleza del sujeto que enuncia; una indeterminación y ambigüedad comunes a toda forma humorística, pero que en el caso antillano adoptó la forma de una actitud subversiva frente a todo intento de establecer un centro de autoridad, articulándose así una práctica cultural anárquica como la del cimarronaje afro-antillano y ese ethos que en Puerto Rico se denomina el "relajo". El relajo puertorriqueño determina, precisamente, la flexibilización de las normas sociales de conducta y respeto que enmarcan el trato entre las distintas clases sociales. ${ }^{8}$ Es interesante la apreciación que hace Alberto Sandoval Sánchez respecto a este ethos puertorriqueño cuando señala que la guachafita, el relajo, el gufeo, etc, responden al hecho de que este tipo de prácticas culturales constituyen la única opción que les permite a los puerto/niuyorriqueños sobrellevar su condición extraterritorial:

What is staged is identity formation not only for the U.S.-born Puerto Rican generation, the so-called Nuyoricans, but also for the Puerto Ricans themselves on the island. Their displacements, replacements, dislocations, relocations, alienation, uprooting, separation are mediated and negotiated through "el gufeo, el vacilón, el relajo, el desorden, la bachata, la chabacanería” in the only way for Puerto Ricans to cope with their deterritorialization and reterritorialization. $(1997,199)$

Precisamente, la puertorriqueñidad de los niuyorriqueños estribaría en ese ethos de raíces antillanas. A falta de un vínculo telúrico con la patria, el gufeo niuyorriqueño se volvería así un núcleo de puertorriqueñidad con el cual resistir los embates asimilacionistas y marginalizantes tanto de la sociedad norteamericana hegemónica como de la cultura puertorriqueña insular criolla. Es esta misma línea de pensamiento la que sigue Efraín Barradas cuando explica el modo en que los poetas niuyorriqueños (neorriqueños los llama Barradas) piensan su puertorriqueñidad:

Para la mayoría de los poetas neorriqueños el ser puertorriqueño, el ser ellos mismos, no radica en un mito de la tierra sino en un estado de ánimo. Ser puertorriqueños para el poeta neorrican es definirse no en términos del lugar de nacimiento, no en términos de la lengua que habla, sino en términos de su actitud vital $(1988,72)$ 
Es esta actitud vital niuyorriqueña, en la que se entrelazan el poder contradiscursivo del humor irreverente y una ética del goce, la que constituye la potencia somática de estas prácticas culturales populares. Se trata, en definitiva, de la capacidad de estos sujetos marginales de transformar su condición subalterna y su aparente improductividad en espacios de resistencia a través del gufeo como instancia fruitiva de un ethos cuya potencia contradiscursiva no se encuentra en su capacidad para confrontar su dimensión marginal intentando modificar sus condiciones materiales, sino en su habilidad para eludir por medio del humor y el goce su poder disciplinante, creando espacios donde éste no impida el ejercicio de la voluntad de estos sujetos oprimidos. Esta ética del goce desarrolla una recuperación de la dimensión fruitiva que establece al cuerpo como espacio de resistencia y subversión. Se trata de la articulación de la cultura corporal subversiva y fruitiva de la música y la danza antillanas con la práctica irreverente del relajo. Ambas expresiones abrevan en la misma cultura caribeña de raíz africana y se entrelazan no sólo a través de la dimensión fruitiva del gozo propuesto y proyectado por ambas, sino también por medio de esa esencial búsqueda insurgente de trasgredir, cuando no abolir, un orden en tanto imposición y sumisión, encierro y clausura que el baile y la risa buscan traspasar, precisamente, por medio del movimiento y el goce. Esta articulación antillana le permitió a la cultura niuyorriqueña superar la política agonística que había dominado en sus inicios y empoderar, en cambio, el componente lúdico y fruitivo de su resistencia cultural, tal como señala, por ejemplo, Héctor Manuel Colón para el caso del género musical de la salsa y sus letras hilarantes:

La Salsa no es música de protesta política. Recordemos aquí que existen muchas piezas de Salsa abiertamente reaccionarias en su letra. Porque esto, señores, no son cantos gregorianos, esto es Salsa ...

Este antiguo pensamiento, reinterpretado por cada generación desde las calles más diversas, busca siempre jugar con las fuerzas para reproducir la vida, juega con la vida y la muerte, el sexo y la represión, el dolor y el placer. Juega con ellas y jugar es burlarse de ellas y en esta música siempre hay burla, burla al opresor, burla a la mujer sensual, burla al macho. (1985: 48) 


\section{3. “iAY, VIRGEN, YO NO SÉ HABLAR!”: EL HUMOR COMO TÁCTICA POLÍTICA}

La humoricidad irreverente de la poesía niuyorriqueña constituye, como vemos, un mecanismo de supervivencia frente a la marginalización y el solapamiento al que se ven recluidos los niuyorriqueños en tanto minoría, configurando, consecuentemente, una praxis política capaz de trascender la hasta entonces privilegiada "escritura comprometida" de la literatura niuyorriqueña, praxis político-literaria promovida principalmente por Miguel Algarín en tanto fundador y cabeza de este movimiento. A diferencia de la literatura comprometida y su ponderación de la confrontación y el agonismo por medio de la denuncia y la proclama exhortativa, las tácticas de resistencia cultural desarrolladas a través del humor antillano reinscriben la identidad cultural niuyorriqueña en la historia afro-antillana, tal como ésta es pensada y definida por el poeta e intelectual martiqueño Édouard Glissant (2005, 2006), como la historia de una red implacable de subordinaciones e interdicciones que motivó la emergencia de una cultura de resistencia discontinua y fragmentaria. Esta cultura afro-antillana se valía, calibanescamente, 9 de la cultura del amo para ejercer a través, y por dentro de la misma, una distorsión subversiva. De allí que esta cultura del desvío ${ }^{10}$ se desarrollase, fundamentalmente, a través de la lengua, por medio de las inflexiones lingüísticas operadas por lo que Glissant denomina la creolización, un movimiento lingüístico que opera por medio de la fragmentariedad, la difracción y la opacidad de la cultura antillana. ${ }^{11}$ Esta creolización designa una "maraña multilingüística y multirracial que creó nudos inextricables en la red de filiaciones, rompiendo así la claridad y linealidad del pensamiento occidental" (Glissant, 2006, 72). ${ }^{12}$

El humor niuyorriqueño de raíz antillana se sostiene, por tanto, en la incongruencia que atraviesa la identidad puertorriqueña a partir de su historia colonial. Desde sus orígenes la cultura puertorriqueña se encontró atravesada por las potencias coloniales (hispánica en el pasado y norteamericana en el presente), situación colonial que configuró una identidad tensada pendular y permanentemente entre estos dos polos contrapuestos: lo hispano-americano y lo anglo-norteamericano. El humor distintivo de esta cultura intersticial constituye, como ya señalamos, una estrategia de supervivencia orientada a resistir los embates permanentes de la asimilación cultural y la situación de marginalidad socio-cultural a la que se relegó históricamente a este colectivo minoritario. De este modo la condición híbrida e impura, junto con las miserias cotidianas a las que se somete a la cultura niuyorriqueña, son expresadas tanto 
en el folklore popular como en las expresiones artísticas de los puertorriqueños de acá y de allá, a través de un humor desenfadado y socarrón que se regodea y se burla de su identidad incongruente y de su aparente situación deficitaria desarticulando la tragicidad de esta condición subalterna y resistiendo por medio de la profanación burlesca el poder opresivo de este sistema hegemónico. ${ }^{13}$

Es importante comprender, como señala Israel Reyes en la introducción a su estudio sobre el humor y la excentricidad en la literatura puertorriqueña, que estas expresiones humorísticas puertorriqueñas operan "obteniendo un placer humorístico de las múltiples contradicciones de la identidad nacional no por medio de su trivialización, sino como medio de superar su pathos de incongruencia” (2005, 2, mi traducción). Se trata entonces de una praxis política contra-hegemónica que, lejos de resignarse frente a las potencias que la subalternizan, las confronta desarticulando el sistema de imposiciones y jerarquías sobre el que se funda su dominación. Este uso del humor como mecanismo de resistencia configura aquello que Michel de Certeau analizó a través de las "tácticas" de los practicantes de una cultura, tácticas por medio de las cuales de Certeau distinguía las operatorias que articulan el "consumo" y el "uso" cultural en la creatividad popular, tácticas que permiten resistir desde dentro desarticulando el sistema hegemónico de una cultura dada. Se trata de "tácticas político-culturales" antes que estrategias, atendiendo a la diferenciación establecida por de Certeau entre la "estrategia" como praxis agonística sostenida sobre la configuración de un lugar propio enfrentado a un otro exteriorizado como totalidad, y la "táctica" como ese mecanismo que se vale de su imposibilidad de situarse por fuera del otro para ejercer resistencias desde el propio seno de la otredad, sacando provecho artera y sutilmente del carácter de provisoriedad y heterogeneidad de su hibridez constitutiva:

Llamo "estrategia" al cálculo de relaciones de fuerzas que se vuelve posible a partir del momento en que un sujeto de voluntad y de poder es susceptible de aislarse de un "ambiente"...

Por el contrario, llamo "táctica" a un cálculo que no puede contar con un lugar propio, ni por tanto con una frontera que distinga al otro como una totalidad visible. La táctica no tiene más lugar que el del otro. Se insinúa, fragmentariamente, sin tomarlo en su totalidad, sin poder mantenerlo a distancia. No dispone de una base donde capitalizar sus ventajas, preparar sus expansiones y asegurar una independencia en relación con las circunstancias. 
Lo "propio" es una victoria del lugar sobre el tiempo. Al contrario, debido a su no lugar, la táctica depende del tiempo, atenta a "coger al vuelo" las posibilidades de provecho. (2000, XLIX-L)

Estas tácticas político-culturales de resistencia que la poesía niuyorriqueña ha configurado a través del humor irreverente y desfachatado de la guachafita y el gufeo y sus procesos de carnavalización de los poderes opresivos de la sociedad exhiben todo su potencial contra-hegemónico en obras como la del poeta niuyorriqueño Tato Laviera.

La publicación por parte de Tato Laviera en 1979 de su primer poemario, La carreta made a U-turn, significó una reformulación de los lineamientos que habían guiado a los poetas niuyorriqueños bajo la figura tutelar de Miguel Algarín, al tiempo que recuperó el legado cultural antillano de Puerto Rico a partir de ciertos elementos históricamente solapados dentro de la historia cultural puertorriqueña. La lengua poética de Laviera es una lengua anclada en la tradición africana del Caribe y su creolización, su fusión de ritmos y acentos foráneos conjugados bajo el espacio comunal del Caribe negro de los esclavos, su carnaval y polirritmia. Los ritmos afro-antillanos que atraviesan toda la obra de Laviera recuperan el legado africano y antillano de la identidad niuyorriqueña sin por ello subordinar ésta a un origen dado, sino apropiándose del carácter transcultural y diaspórico de la historia cultural antillana para integrarla al sistema relacional y rizomático de tradiciones culturales que conforman la identidad niuyorriqueña, y articulando también esta polirritmia afro-antillana dentro de la praxis cultural del vacilón y la guachafita puertorriqueñas. Ejemplo de ello lo constituye el difundido poema de Laviera "My graduation speech":

i think in spanish

i write in english

i want to go back to puerto rico, but $\mathrm{i}$ wonder if my kink could live in ponce, mayagüez and carolina

tengo las venas aculturadas

escribo in spanglish

abraham in español

abraham in english

tato in spanish 


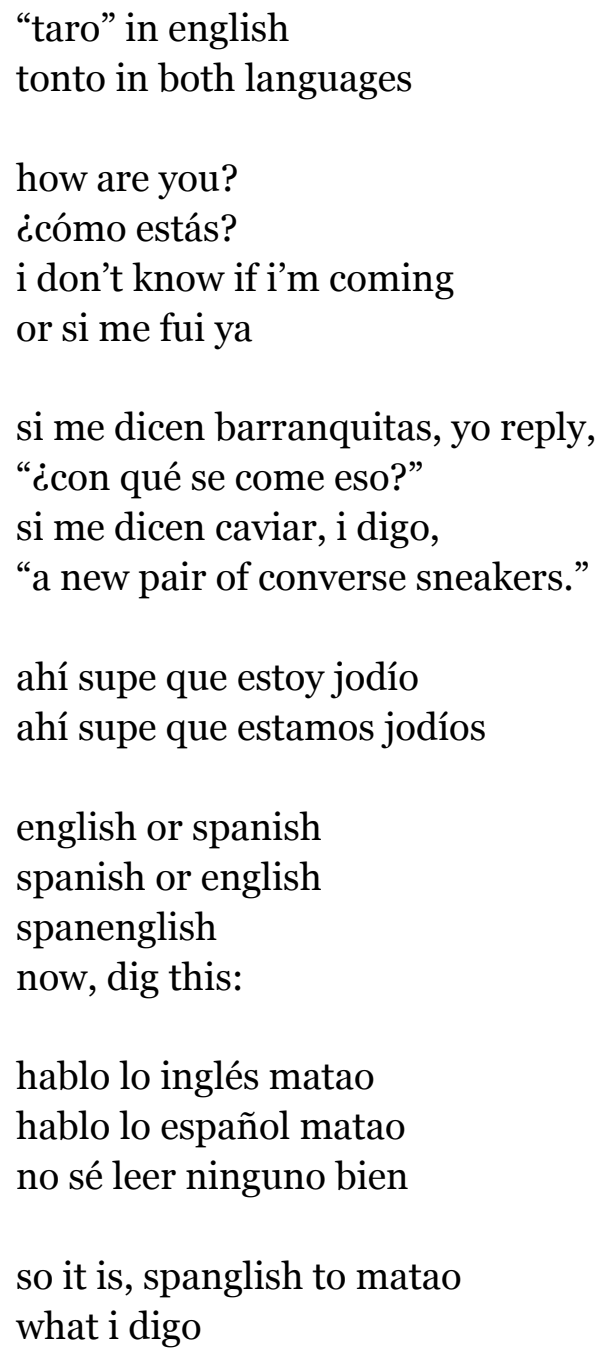

iay, virgen, yo no sé hablar! (Laviera, 1979, 17)

En "my graduation speech" Laviera no sólo construye una identidad niuyorriqueña a partir del uso interlingüe de un espectro de registros vernáculos que conjuga el español y el inglés estándar con el habla coloquial afro-americana y afro-antillana, sino además por medio de ese ethos irreverente que hemos identificado con el vacilón y el relajo caribeños. A su vez, el poema de Laviera subvierte los mecanismos opresivos de estigmatización y subalternización que censuran esta identidad híbrida bajo el imaginario de un sujeto y una cultura deficitarios. El verso final del poema se aproxima, precisamente, al lema de la docilidad puertorriqueña simbolizada en la expresión popular "ay bendito", ${ }^{14}$ cuya pura condición interjectiva materializaría la impotencia factual del sujeto subalterno, pero que con el poema de Laviera se vuelve algo más, por cuanto la ironía y el humor que vibran en estos versos transforman las aparentes 
carencias y debilidad de este sujeto deficitario en una resistencia táctica. Este imaginario del déficit cultural es subvertido en el poema por medio de su parodización y del humor irónico con el cual Laviera desconstruye y desarticula sus presupuestos a través de la creatividad expresiva emergente en esos "mal-entendidos" y "mal-pronunciamientos" sobre los que se construye el poema. De esta aparente condición cultural deficitaria emerge el trabajo del poema con ese humor corrosivo que produce una auto-parodización bajo la figura de un yo lírico "analfabeto", el cual confunde las palabras y procede a mezclarlas agramaticalmente. Esto redunda, finalmente, en esa exclamación recargada de comicidad e ironía y reforzada por los versos finales: “ahí supe que estoy jodío / ahí supe que estamos jodíos". ${ }^{15}$ La subversión de este juicio despectivo, que estigmatiza al sujeto "jodido" bajo el peso de su aparente déficit lingüístico-cultural, se potencia por medio de la "joda” con que este sujeto lírico se burla de sus supuestas falencias e incapacidades lingüísticas, mientras construye, al mismo tiempo, un discurso poético a través del cual ironiza y parodia este imaginario estigmatizante y por consecuencia lo “jode”, lo anula, lo trasgrede, lo subvierte.

El poder corrosivo y contradiscursivo de estas expresiones poéticas del humor antillano se sostiene principalmente en la naturaleza performativa y oral de esta tradición literaria. Como señala Juan Otero Garabís en su análisis de la novela del puertorriqueño Luis Rafael Sánchez La guaracha del Macho Camacho (1976), la potencia contradiscursiva del relajo o vacilón puertorriqueño que introduce la obra de Sánchez se sostiene a partir de una escritura que se instituye como un espacio de goce desde el cual resistir y corregir el desorden social, mientras que esta misma contradiscursividad es llevada a sus límites y emponderada plenamente a través de otras expresiones culturales propias de la música popular puertorriqueña como, por ejemplo, la salsa de Eddie Palmieri, cuyos ritmos sincopados y frenéticos subvierten la opresión y el disciplinamiento social oponiendo "el vacilón al orden, no de manera sistemática, sino de manera liberadora" (Otero Garabís, 2000, 96). De igual modo, los ritmos afro-antillanos que gobiernan muchos de los poemas de Tato Laviera, por ejemplo, insisten en esta potencia subversiva y liberadora de la música antillana cuya dimensión fruitiva establece al cuerpo como un espacio de resistencia a través del goce.

Todo este relajo antillano funda así un humor corrosivo cuyo poder subyace en ese lenguaje despojado y directo con el que se introduce el giro inesperado y conmocionante de la carcajada, esa descarga somática y fruitiva que disloca la seriedad y formalidad de cualquier situación a través de su alto grado de informalidad, 
irrespetuosidad y desubicación. La incongruencia expuesta por este humor antillano es la que desata una carcajada que, lejos de investirse con el poder reflexivo del humor de corte intelectual, exige el exceso purificador de la risotada. El poema de Víctor Hernández Cruz que veíamos como ejemplo de la "tropicalización" enunciada por Frances Aparicio se inscribe en un tríptico titulado "Three Songs From the 50's", donde Hernández Cruz hace gala de su habilidad para usufructuar estos diversos tipos de humor. Si bien en "Song 2" el humor era capaz de promover una reflexión intelectual al exigir reponer un contexto cultural generador del efecto irrisorio, en el poema que abre el tríptico, en cambio, Hernández Cruz construye un tipo de humoricidad más apegada a estas expresiones culturales antillanas populares del relajo y la guachafita:

Julito used to shine the soul
of his shoes before he left for
the Palladium to take the wax
off the floor while Tito Rodríguez
flew around the walls like a
parakeet choking maracas
It was around this time that
Julito threw away his cape
because the Umbrella Man and the
Dragons put the heat on all the
Ricans who used to fly around
in Dracula capes swinging canes
or carrying umbrellas
Even if there was no rain
on the horizon
That same epoca my mother
got the urge to paint the
living room pink and buy a
new mirror with flamingoes
elegantly on the right hand
corner because the one we had
was broken from the time that
Carlos tried to put some respect
Into Julito and knock the
party out of him. (1989, 82 )

Este poema aborda un acontecimiento importante de la historia cultural niuyorriqueña como fue el caso criminal de los pandilleros apodados "Capeman" y "Umbrella man", quienes asesinaron brutalmente a dos adolescentes en un contexto de 
violencia cotidiana entre las distintas pandillas y gangsters de Nueva York durante la década del cincuenta, entre ellas, la pandilla puertorriqueña conocida como los "Dragones”. Este contexto histórico es repuesto por Hernández Cruz con el título que le da a su tríptico: "Tres Canciones de los 50". Sin embargo, lo que constituye el carácter antillano del poema es el modo en que Cruz aborda este tema delicado para la historia niuyorriqueña, el cual impuso a la comunidad un estigma duradero en gran medida por la difusión masiva del caso en los grandes medios y la consiguiente demonización de la identidad étnico-cultural puertorriqueña en los Estados Unidos. Que el poema aborde este contexto histórico-cultural conflictivo a través del humor y el desparpajo con que se lo trata es lo que lo inscribe dentro de la práctica de raíces antillanas del gufeo, al descolocar por medio de la irreverencia la seriedad del asunto.

Lo que podría haber dado lugar a una denuncia de la situación de marginalización, estigmatización y opresión de la comunidad puertorriqueña en Nueva York da lugar, en cambio, en el poema de Hernández Cruz a la representación jocosa de esta situación acuciante para la comunidad. Así, la figura central del poema, Julito, un puertorriqueño que gasta la pista del emblemático Palladium, escenario consagratorio para la salsa de Tito Rodríguez, debe dejar a un lado su habitual capa y paraguas porque el Umbrella man y la banda de los Dragones pusieron en aprietos a los puertorriqueños que "solían dar vueltas con capas de Drácula", blandiendo bastones o paraguas incluso cuando "no había lluvia en el horizonte". La ironía que acompaña esta descripción de los trágicos eventos que tuvieron como protagonistas a los gangsters puertorriqueños genera un efecto humorístico que desarticula la tragicidad y seriedad de los mismos. Y este humor irónico es reforzado por los versos siguientes que asimilan esta época trágica para la historia de la comunidad con la estética kitsch caribeña que la madre de Julito le imprime a su hogar, operando una duplicación de la imagen estereotipada y estigmatizada de la identidad cultural niuyorriqueña: el crimen y la tropicalidad.

Otro ejemplo de este uso poético-político de la irreverente humoricidad antillana en la poesía niuyorriqueña lo constituye la obra de otro emblema de esta tradición literaria, como es Pedro Pietri. Pietri desarrolló durante la década del 70, y a partir del formato del chiste, toda una serie de composiciones poéticas tituladas a partir de la numeración de las cabinas telefónicas de la ciudad de Nueva York. Esta serie reunía poemas construidos a partir de la plasticidad y la potencia del registro oral coloquial y de un tono sobrecargado de la burla y jocosidad características de la cultura 
niuyorriqueña del gufeo. Poemas como “Telephone Booth Number 905 1/2" subvierten, por ejemplo, a través del humor y del desparpajo de la voz del yo lírico, la opresión de la cultura capitalista del trabajo que somete al niuyorriqueño a ocupar pasivamente su rol de asalariado explotado dentro de la jerarquía social:

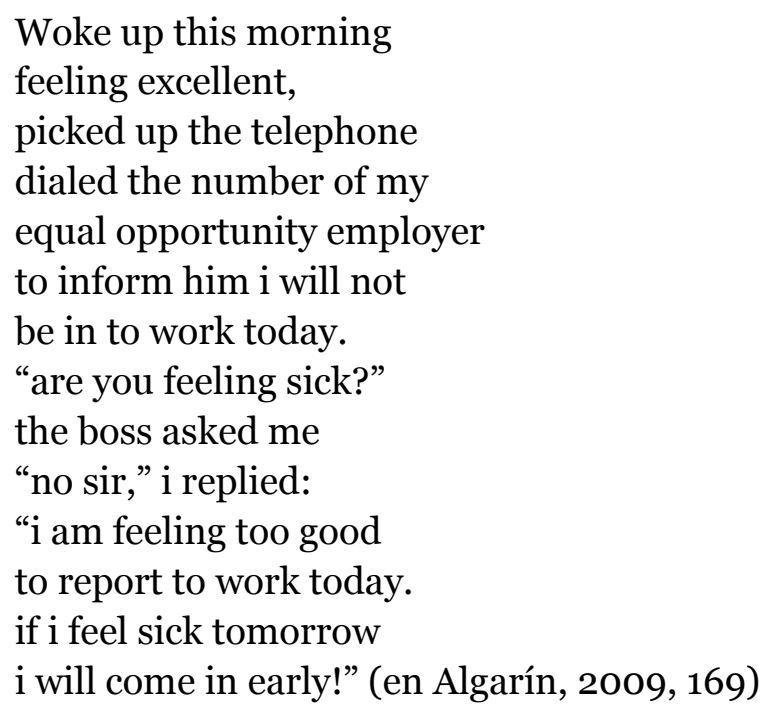

Mientras que en su hito literario "Puerto Rican Obituary" (1969), poema con valor fundacional para la tradición niuyorriqueña, Pietri enfatizaba esta dimensión opresiva, alienante y fatídica de la explotación laboral de la comunidad, en su serie "Telephone Booth Number", en cambio, escoge indagar en el potencial contra-discursivo del humor y de la corrosiva cultura del gufeo frente a la situación de explotación y opresión. En "Telephone Booth \#905 1/2", esta subversión opera mediante la "felicidad" experimentada por el yo lírico y su naturaleza ociosa. A su vez, este estado dichoso del ocio promueve la burla y el relajo frente a la voz inquisitiva del patrón cuya última respuesta es acallada por la chanza irreverente con que se le niega cualquier posibilidad de restaurar la condición de explotación trascendida en un principio. El formato del chiste con su brevedad y concisión, y con su naturaleza oral y coloquial, le permiten a Pietri desarrollar esta dimensión subversiva del gufeo frente a la condición de subalternidad.

Otro ejemplo más de cómo Pietri alcanza esta articulación entre la condición subalterna de la cultura niuyorriqueña y su lúdica y fruitiva potencia contrahegemónica es el poema satírico "Suicide note from a Cockroach in a low income Housing Project”, en el cual Pietri adopta la voz de una miserable cucaracha cuya 
situación ruinosa la lleva a tomar la decisión del suicidio. En este poema Pietri se vale de uno de los elementos residuales y simbólicos de la miseria a la que se ve condenada su comunidad: la cucaracha, tópico literario de la degradación niuyorriqueña con el cual Pietri, a través de un fuerte tono irónico y satírico, expresa los padecimientos de un ser miserable y desfalleciente de hambre sumergido en la pobreza más extrema escenificada por el espacio identitario de la cultura niuyorriqueña: los project, apartamentos de asistencia social que constituyen el escenario típico de muchos de los poemas contestatarios de esta primera generación poética. Otro poema de Pietri que ejemplifica este humor corrosivo lo constituye "El Spanglish National Anthem”, poema que parodiza los tópicos tradicionales de la primera literatura puertorriqueña del exilio, generación caracterizada por su tono nostálgico y una pulsión omnipresente por el regreso, como ocurre, por ejemplo, en la famosa canción del compositor puertorriqueño Noel Estrada "En mi viejo San Juan”, himno de esta tradición de la nostalgia insular. La canción de Estrada es recuperada por Pietri en "El Spanglish National Anthem" para ejercer una parodia que la transforma en un nuevo "himno spanglish" de la condición intersticial niuyorriqueña. Pietri subvierte así en su poema esa cultura del exilio centrada en el telurismo de la patria por medio del humor. En el poema el "viejo San Juan" pasa de ser un espacio idealizado que centrífugamente pulsiona el regreso, a ser un espacio centrípeto de expulsión y rechazo de las clases populares:

\author{
En my Viejo San Juan \\ They raise the price of pan \\ So I fly to Manhattan. \\ It was there that I swear \\ Everyone took welfare \\ Especially the Latins! \\ To El Barrio I went \\ In pursuit of low rent \\ In a five room apartment \\ Where by neighbors will be \\ Puerto Ricans like me \\ Dressed in tropical garments. (Pietri, online)
}

El uso paródico de la letra de Estrada y de sus estructuras (el estribillo, la rima consonante, etc.) construyen el humor desfachatado que modula la subversión operada 
por el poema de Pietri. Es la cultura insular, el "viejo San Juan”, la que configura aquí el espacio de la miseria, el espacio que les niega el pan a sus habitantes y los impulsa al desplazamiento. Este desplazamiento, lejos de configurar un destierro y un proceso de aculturación, consigna, en cambio, la posibilidad de restituir la cultura puertorriqueña extraterritorialmente. De este modo, "el Barrio", ese espacio transformado y apropiado por la cultura latina migrante, se vuelve un núcleo para la articulación de una nueva identidad fundida en la tropicalidad de las guayaberas, la cual, si bien no puede restaurar el paisaje (las "palmas" que extraña el yo poético), sin embargo, se afianza como nuevo espacio comunitario bajo el marcador cultural de lo "latino" y habilita así la identificación colectiva.

Pero la pulsión por el regreso no desaparece, y si bien es parodiada a través de su postergación ("hasta que salgan los números de la lotería”), la isla permanece latente como un espacio prometido de redención frente a las penurias y la marginación experimentada en los Estados Unidos. Poemas como "El Spanglish National Anthem" exponen esa vacilación idiosincrática niuyorriqueña que oscila a través de la tensión entre la aceptación de su nueva situación intersticial y la posibilidad del regreso a las "raíces". Esta tensión asume en la poesía de Pietri la forma del humor y el vacilón antillanos, de modo tal que el sentimiento de opresión experimentado por las condiciones de marginalidad y explotación cede paso a la irrupción de un tono jocoso por medio del cual el poema se burla del propio sueño de retorno a la isla, en primer lugar relegándolo a la posibilidad incierta de ganar la lotería, y luego, en un verso plagado de este humor desfachatado, mandando todo "al carajo" y expresando así la voluntad de realizar el proyecto de retorno nadando desde El Barrio neoyorquino hasta Puerto Rico:

\author{
I know \\ I know I know \\ I'll reach Puerto Rico \\ (Y live to be ninety three) \\ And so And so \\ Once in Puerto Rico \\ (Won't be a minority) \\ Y Paaaaa' \\ El carajo with the numbers \\ If I can't fly I'll swim \\ Straight from El Barrio
}


Back to Puerto Rico

(Island by the sun blessed

Island I never left

I will settle there next) (Pietri, online)

De este modo Pietri cancela la posibilidad efectiva de instaurar el regreso como un proyecto posible de superación de la marginalidad niuyorriqueña, pero posibilita, en cambio, la latencia de esta pulsión en tanto vínculo con la cultura popular de la isla, un vínculo establecido a partir de ese ethos irreverente y desfachatado que promueve el humor antillano de su poética y su capacidad de tomar con sorna y volver risibles aspectos tan candentes y trágicos de la vida niuyorriqueña, como son la marginalidad, la subalternidad y la extraterritorialidad de su historia diaspórica.

\section{ESOS NEGROS PARAOS NIUYORRIQUEÑOS: LA SUBVERSIÓN DEL HUMOR DISPARATERO}

En la obra de Tato Laviera la condición oprimida y marginal de la comunidad niuyorriqueña también es abordada, al igual que lo hacía Pedro Pietri, a través del humor irreverente y corrosivo del gufeo. Es esta representación burlesca la que emerge, por ejemplo, en poemas de Laviera como "Praying", donde se retrata la súplica que los puertorriqueños le dirigen a un Dios hastiado de escuchar sus quejas:

papa dios está agallao, ya no puede soportar los "puerto ricans" están orando overtime no dejamos dormir a dios, está volviéndose loco con las comiquerías de nosotros, siempre chavándole la vida, papá dios está prendío, los "puerto ricans" están "overloading the circuits with numerous requests" ...

papá dios got up and said ... "Bendito, they work so hard, bendito, they are so passive, i never get angry with my worthy faithful subjects, it is just that some crazy puerto rican poet is misinforming the people, i'm not enfogonao," papá dios ordered a new computerized system to solve the inundation problem, but papá dios said to please tell them puerto ricans that he'll listen to their every desire, if they will give papá dios un brakecito, concho, "y déjenme dormir. De vez en cuando duerman ustedes, por favor." (1985, 72-73) 
Aquí la denuncia y la protesta se integran y potencian por medio de la desacralización y la irreverente humorada con que Laviera da cuenta, a través del tono coloquial del habla popular y su registro vernáculo afro-antillano, de la situación de desamparo y marginalidad, al tiempo que consigna esa actitud cultural propiamente antillana del relajo, idiosincrasia a través de la cual estos sujetos marginados logran resistir y subvertir la cultura hegemónica y sus dispositivos de asimilación y subalternización cultural por medio de la desarticulación y dislocación de ese discurso que los construye como sujetos deficitarios, o bien como víctimas pasivas.

Es necesario aclarar que este tipo de subversiones culturales no confrontan directamente el orden social hegemónico procurando acabarlo o reemplazarlo por otro más igualitario, sino que su praxis política contra-discursiva se da en el terreno del lenguaje, es decir, en el espacio cultural de los imaginarios instituidos y de las prerrogativas sobre lo pensable y lo decible. ${ }^{16}$ Esta subversión cultural desarrollada por el humor antillano del gufeo niuyorriqueño opera, de este modo, a partir de la condición diaspórica y liminal de esta cultura híbrida. Y es en virtud de esta intersticialidad identitaria que la poesía niuyorriqueña ejerce una resistencia, tanto frente a la cultura hegemónica norteamericana, como frente a la cultura hegemónica puertorriqueña insular, pero sin hacerlo por fuera de las mismas, sino apelando al poder corrosivo del entremedio, ese espacio subversivo que, como señala Homi Bhabha, "subvierte la autoridad, no clamando su total diferencia respecto a ésta, sino usando imágenes autorizadas en contra suya para revelar una historia diferente. Una subversión que interviene en los intersticios" (2005, 190, mi traducción).

Es esta cultura lúdica y subversiva de raíz antillana la que, en definitiva, configura el tipo de acentuación con que deben ser leídos y experimentados estos poemas niuyorriqueños (concebidos, esencialmente, para ser recitados), y es esta misma actitud lúdica, humorística e irreverente la que estos poetas recuperaron de la cultura popular puertorriqueña y sobre la cual conformaron la base de la identidad cultural desplegada en sus obras. Esta identidad cultural se sostiene frente al patrón dominante norteamericano en la disposición insurrecta del cimarronaje antillano y su desparpajo pícaramente subversivo, en esa lengua insurgente blandeada por los "negros paraos" de las plantaciones caribeñas frente al silencio impuesto por el orden colonial, esos esclavos que, como señala Héctor Manuel Colón, plantaban bandera a sus patrones por medio de su irreverente desfachatez: 
Nos topamos ahora con un grupo de poetas niuyorricans. Unos muchachos maleducados e irreverentes que ante la transculturación que denuncian los independentistas puertorriqueños-esa forma tan científica de llorar la hacienda y el señorío que perdieron-, ante la denuncia de todo lo que pierden con el imperialismo, estos muchachos denuncian lo que tienen, lo que les sobra. Esa lengua viva, plástica, cuya desfachatez trajeron de las Antillas, de aquellos antillanos que los hacendados llamaban "negros paraos" $(1985,83)$

Vemos así que poéticas como las Tato Laviera, Víctor Hernández Cruz o Pedro Pietri logran articular estas tácticas de supervivencia y resistencia cultural pertenecientes a la tradición afro-antillana con el humor desarrollado en el gufeo. Estos autores constituyen, por consiguiente, un ejemplo de cómo es posible configurar una subversión irreverente a partir del humor y de una poética de la "diversión", esto es, una poética que logra divergir los dispositivos de control y subordinación socio-cultural por medio de los mecanismos fragmentarios y difractivos del humor. Y es, precisamente, esta potencia insurgente la que promueve la apelación recurrente de los poetas niuyorriqueños a esa modulación típica del humor popular por medio del cual la lacerante condición de la vida en los márgenes es capaz de ceder lugar, en cambio, al regocijo hilarante de una lengua poética disparatera, como llama el propio Tato Laviera a esa lengua capaz de disparar contra la opresión y la subalternización por medio de su dispar y disparatada risa insolente:

LA VIDA es un inglés frío un español no preciso un spanglish disparatero ... (Laviera, 1981, 33)

\section{NOTAS}

1 El verbo spanglish "gufear" (y su sustantivación "el gufeo") provienen del inglés coloquial to goof around o goof on ("bobear", "burlarse").

2 El neologismo spanglish nuyorican es traducido al español de diversos modos, entre los cuales se encuentran: nuyorriqueño, neorriqueño, niuyorrican o niuyorriqueño. Optamos por esta última traducción en virtud de su proximidad homofónica con el original spanglish. La homofonía ocupa un lugar central en las construcciones lingüísticas del spanglish, el cual en virtud de su desnormatividad léxica y sintáctica posibilita esta profusión de traducciones, no obstante lo cual, tal como señala Jorge Duany, el único término incapaz de dar cuenta de esta identidad cultural es "puertorriqueño-estadounidense": "los críticos ni siquiera pueden ponerse de acuerdo en un término común para referirse a los puertorriqueños de los Estados 
Unidos. Las ponencias para la Conferencia de la Asociación de Estudios Puertorriqueños celebrada en San Juan en 1996 sugería las siguientes alternativas: Neo-Rican, Nuyorican, Niuyorrican, nuyorriqueño, puertorriqueño continental, puertorriqueño de los Estados Unidos, boricua, diasporiqueño, e incluso el curioso neologismo de Tato Laviera AmeRícan -pero nunca esa mezcla entreguionada, puertorriqueño-estadounidense” (Duany, 2002, 28).

3 WASP corresponde al acrónimo que designa a la cultura hegemónica estadounidense: "White Anglo-Saxon Protestant".

4 Utilizo el concepto extraterritorialidad como condición fronteriza del escritor moderno desplazado y su particular relación de extranjería frente a la lengua, tal como fuera desarrollado por George Steiner en su obra Extraterritorial (2002).

5 Julio Ramos (2002) observa respecto a este poder corrosivo de la literatura latina y el denominado campo de los Estudios Latinos dentro de la crítica académica en los Estados Unidos, que los críticos, intelectuales y escritores latinos condujeron a una redefinición de los límites tradicionales del Latinoamericanismo en tanto disciplina, al desestabilizar nociones tales como las de pureza lingüística, o la de una relación fija y unívoca con el lugar de origen y la lengua materna.

6 San Martín de Porres Velázquez, conocido también como "el santo de la escoba", fue un fraile dominico nacido en Lima en 1579, hijo de un hidalgo burgalés y una negra liberta de Panamá. Fue beatificado en el siglo XIX y canonizado en 1962, convirtiéndose en el primer santo mulato de América. Figura de devoción en los sectores populares, su nombre quedó íntimamente ligado a la religiosidad de los oprimidos, especialmente indígenas, negros y mulatos. Se lo reconoce como el "santo patrono de la justicia social" en virtud de su humildad, su compromiso con los más desposeídos y su apostolado de la caridad.

7 Los vínculos entre las tradiciones culturales afro-americana y afro-antillana son profusos y dieron lugar a movimientos como el de los Last Poets en la década del sesenta, movimiento político-cultural surgido en los Estados Unidos que reunió diversas figuras, entre las cuales se encontraba el activista y poeta Felipe Luciano, uno de los fundadores del movimiento niuyorriqueño. Estos vínculos se expresaron, a su vez, en el campo socio-político, por ejemplo, a través de la estrecha relación entre movimientos afro-americanos como el "New Negro" o los "Black Panthers" y movimientos afro-antillanos, dentro y fuera de los Estados Unidos, como el de los "Young Lords" o el movimiento caribeño de la "Negritude". Para un estudio de esta relación, ver W. Feuser, "Afro-American Literature and Negritude" (1976) y el capítulo "Puerto Rican American Poetry" del libro de William Luis, Dances Between Two Cultures: Latino Caribbean Literature Written in the United States (2001, 37-98).

8 Sobre la condición popular del relajo puertorriqueño y su relación con el gufeo niuyorriqueño, ver J. Flores, Divided Borders (1993, 199-224).

9 Este mecanismo "calibanesco" surge del personaje de Calibán en el drama de Shakespeare La tempestad, obra que fue reapropiada por toda una tradición crítica del pensamiento latinoamericano para iluminar la identidad cultural del continente, por ejemplo, en el célebre ensayo Ariel (1900), del intelectual uruguayo José Rodó, y en el pensamiento del intelectual cubano Roberto Fernández Retamar con su ensayo Calibán (1971). En este último la figura de Calibán es puesta en primer plano como sujeto subalterno que se apropia de la lengua del amo para usarla en su contra, promoviendo así esta adjetivación del término "calibanesco" de la cual hacemos uso en nuestro trabajo. Sobre la evolución de la figura de Calibán y sus usos en la ensayística y en el pensamiento latinoamericano y antillano ver la tesis doctoral de Florencia Bonfiglio Travesías de la religación en el siglo XX: apropiaciones de La tempestad de Shakespeare en la literatura latinoamericana y caribeña (2012). 
10 El détour (rodeo, desvío) es descripto por Édouard Glissant como una estrategia de supervivencia desarrollada por los esclavos africanos de las Antillas para poder hablar desde el silencio impuesto por el orden colonial, para ejercer rodeos, desvíos y subterfugios por medio de los cuales estos sujetos sin voz lograron sobrevivir culturalmente.

11 Sobre la constitución de esta subversión lingüística en la tradición poética niuyorriqueña, ver mi artículo "La fruición de lo múltiple: la retórica de la impureza en la poesía de Tato Laviera" (2012).

12 Esta cita de Glissant y todas las pertenecientes a su ensayo Poetics of Relation (2006) aparecen con mi traducción al español.

13 Utilizo el concepto de subalternidad siguiendo la definición de Ranajit Guha como término que da "un nombre para el atributo general de la subordinación . . . ya sea que ésta esté expresada en términos de clase, casta, edad, género y oficio o de cualquier otra forma" $(1988,35)$.

14 Arcadio Díaz Quiñones contrapone, en su ensayo El arte de bregar (2000), la "fatalidad y blandura" de la expresión puertorriqueña "ay bendito", con la potencia de esa otra expresión puertorriqueña subsumida en el verbo "bregar". Por su parte, Carolina Sancholuz señala que "esta última frase [ay bendito] que connota el lamento, el pesimismo, fue muy utilizada por los miembros de la Generación del Treinta, y remitía, especialmente, a la imagen de la pérdida y la nostalgia de los modos de vida anteriores a la invasión norteamericana" $(2010,121)$.

15 Términos como "jodío" y "matao" inscriben el acento afro-antillano por medio de la sufijación -ío y -ao, al tiempo que refuerzan ese quiebre de la pureza y estandarización lingüística propio del spanglish. Sobre el uso de la lengua afro-antillana en la poesía de Tato Laviera ver el artículo de J. Flores "Tato(ao): la poética del Eye Dialect” (2010).

16 Esta concepción de la politicidad de la literatura se corresponde con esa forma particular de obrar lo político que instituye el discurso literario como formación de lo experienciable tal como lo piensa Jacques Rancière: "La política de la literatura, entonces, significa que la literatura, en cuanto literatura, se integra en esta partición de lo visible y lo decible, en esta imbricación del ser, el hacer y el decir que enmarca un polémico mundo común" $(2004,10)$. Sobre la articulación entre literatura y política en la tradición poética niuyorriqueña, ver mi artículo "Activismo, política y subversión en la literatura niuyorriqueña: del programa poético-político de Miguel Algarín a la poética menor de Tato Laviera” (2014).

\section{REFERENCIAS BIBLIOGRÁFICAS}

ALGARÍN, M. y PIÑERO, M. (eds.). 1975. Nuyorican Poetry: An Anthology of Puerto Rican Words and Feelings. Nueva York: Morrow.

ALGARÍN, M. 2009. Survival Supervivencia. Houston: Arte Público Press.

APARICIO, F. 1994. "On Sub-Versive Signifiers: U. S. Latina/o Writers Tropicalize English”, American Literature 66 (4), 795-801. 
BAJTÍN, M. 1989. La cultura popular en la Edad Media y en el Renacimiento: el contexto de François Rabelais. Madrid: Alianza.

BARRADAS, E. 1988. Partes de un todo: ensayos y notas sobre literatura puertorriqueña en los Estados Unidos. San Juan: Editorial de la Universidad de Puerto Rico.

BONFIGLIO, F. 2012. Travesías de la religación en el siglo XX: apropiaciones de La Tempestad de Shakespeare en la literatura latinoamericana y caribeña. Tesis de doctorado por la Universidad de Buenos Aires. MIMEO.

COLÓN, H. M. 1985. "La calle que los marxistas nunca entendieron”, Comunicación y Cultura en América Latina, 14, 81-94.

DE CERTEAU, M. 200o. La invención de lo cotidiano. Las artes de hacer. México: Universidad Iberoamericana-ITESO.

DÍAZ QUIÑONES, A. 200o. El arte de bregar $y$ otros ensayos. San Juan: Ediciones Callejón.

DUANY, J. 2002. The Puerto Rican Nation on the Move: Identities on the Island and in the United States. Chapel Hill: University of North Carolina Press.

ECO, U. 1989. "Los marcos de la 'libertad' cómica”, en Eco, U., Ivanov, V. V. y Rector, M. (eds.), Carnaval. México: Fondo de Cultura Económica, 9-20. . 1999. La estrategia de la ilusión. Barcelona: Lumen.

FEUSER, W. 1976. "Afro-American Literature and Negritude”, Comparative Literature, 28 (4), 289-308.

FLORES, J. 1993. Divided Borders: Essays on Puerto Rican Identity. Houston: Arte Público. . 2010. "Tato(ao): la poética del Eye Dialect", Katatay, VI (8), 157-160.

GATES, H. L. 1988. The Signifying Monkey: A Theory of African-American Literary Criticism. Oxford: Oxford University Press.

GLISSANT, E. 2005. El discurso antillano. Caracas: Monte Ávila. . 2006. Poetics of Relation. Michigan: Michigan University Press.

GUHA, R. 1988. "Preface”, en Guha, R. y Spivak, G. (eds.), Selected Subaltern Studies. Nueva York: Oxford University Press, 35-37.

HERNÁNDEZ CRUZ, V. 1989. Rhythm, Content and Flavour. Houston: Arte Público Press. JENNY, L. 1974. “Le discours du Carnaval”, Litterature, 16, 19-36

LAVIERA, T. 1979. La carreta made a U-turn. Houston: Arte Público Press. . 1985. AmeRícan. Houston: Arte Público Press.

LÓPEZ, A. 2012. "La fruición de lo múltiple: la retórica de la impureza en la poesía de Tato Laviera”, Anclajes 16 (2), 19-37. 
2014. "Activismo, política y subversión en la literatura niuyorriqueña: del programa poético-político de Miguel Algarín a la poética menor de Tato Laviera", Ciencia Política 9 (1), 19-47.

LUIS, W. 2001. Dance Between Two Cultures: Latino Caribbean Literature Written in the United States. Nashville: Vanderbilt University Press.

MAÑACH, J. 1969 [1928]. Indagación del choteo cubano. Miami: Mnemosyne.

MORREALL, J. 1983. Taking Laughter Seriously. Nueva York: State University of New York Press.

OTERO GARABÍS, J. 200o. Nación y ritmo: “descargas" desde el Caribe. San Juan: Ediciones Callejón.

PIETRI, P. 1973. Puerto Rican Obituary. Nueva York/Londres: Monthly Review Press. . El Spanglish National Anthem. Disponible en: http://elpuertoricanembassy.org/ el-spanglish-national-anthem [Consultado 2 mayo 2015].

RAMOS, J. 2002. "Genealogías de la moral latinoamericanista: El cuerpo y la deuda de Flora Tristán”, en Moraña, M. (ed.), Nuevas perspectivas desde-sobre América Latina: El desafío de los estudios culturales. Pittsburgh: Universidad de Pittsburgh, 185-208.

RANCIÈRE, J. 2004. “The Politics of Literature”, SubStance, 103 (33-1), 10-24.

REYES, I. 2005. Humor and the Eccentric Text in Puerto Rican Literature. Gainesville: University of Florida Press.

RODRÍGUEZ MONEGAL, E. 1979. "Carnaval/Antropofagia/Parodia”, Revista Iberoamericana, 45 (108-109), 401-412.

SÁNCHEZ, L. R. 1994. La guagua aérea. San Juan: Editorial Cultural.

SANDOVAL SÁNCHEZ, A. 1997. "Puerto Rican Identity Up in the Air: Air Migration, Its Cultural Representations, and Me -Cruzando el Charco”, en Grosfoguel, R., NegrónMuntaner, F. y Georas, C. S. (eds.), Puerto Rican Jam: Rethinking Colonialism and Nationalism. Minneapolis: University of Minnesota Press, 189-208.

SANCHOLUZ, C. 2010. Mapa de una pasión caribeña: lecturas sobre Edgardo Rodríguez Julia. Buenos Aires: Dunken.

STEINER, G. 2002. Extraterritorial. Madrid: Siruela.

VALDÉS GARCÍA, F. 2004. "El Caribe: integración, identidad y choteo", Utopía y Praxis Latinoamericana, 9 (27), 49-60. 